The Medical Needs, Public Health, and Living Environment following the 1999 Taiwan Earthquake Keiji Nakata, ${ }^{1}$ Norimasa Seo, ${ }^{2}$ Hisayosbi Kondo, ${ }^{3}$ Yuicbi Koido, ${ }^{3}$ Yasubiro Yamamoto ${ }^{3}$

1. Department of Life Science, Hiroshima Bunkyo Women's Junior College, Japan

2. Department of Anesthesiology and Critical Care Medicine, Jichi Medical School, Japan

3. Department of Emergency and Critical Care Medicine, Nippon Medical School, Japan

Objective: To realize the changes of the medical needs, status of public health, and living environment from the acute phase to the sub-acute phase during the dispatch of the Japan Disaster Relief Medical team (JDR medical team) to the 1999 Taiwan earthquake,

Methods: The study was performed by interviewing disaster refugees ( 93 households, 658 persons), and examining the available water and sanitation.

Results: Skin disease, trauma, and respiratory disease were the main problems of the non-seriously injured persons during the early phase. Respiratory diseases increased rapidly with time and were followed by mental or psychological dysfunction, and secondary trauma (not earthquake-related). The state of public health was maintained fairly well, e.g., water and sanitation. As for the living environment, the supplies of food, drinking water, drugs, toilets, sleeping places, shower equipment, amusement facilities, etc. were adequate. However, given the long period of living in tents, mental stress gradually increased.

Conclusion: Fairly good recovery from the acute to the sub-acute phase of the disaster was apparent except for the development of mental problems. The probability for spreading infectious diseases was low.

Keywords: earthquake; living environment; medical needs; public health state

Prehosp Disast Med 2002;17:s18.

\section{Hanshin-Awaji Earthquake and Medical Response: \\ An Overview}

Hiroshi Tanaka

Department of Traumatology, Osaka University Medical School, Osaka, Japan

Objective: To provide an overview of the morbidity and mortality of hospitalized patients following the HanshinAwaji earthquake.

Methods: Medical records of 6,107 patients admitted to 95 hospitals (48 affected hospitals within the disaster area and 47 back-up hospitals in the surrounding area) during the initial 15 days after the earthquake were analyzed retrospectively. Patient census, diagnoses, dispositions, and prognoses were abstracted.

Results: A total of 2,718 patients with earthquake-related injuries were admitted to 95 hospitals, including 372 patients with crush syndrome, 2,346 with other injuries, and 3,389 with illnesses. Seventy-five percent of the injured were hospitalized during the first three days. In contrast, the number of patients with illnesses continued to increase over the entire 15-day period after the earthquake. The mortality rates were $13.4 \%(50 / 372), 5.5 \%$ $(128 / 2,346)$, and $10.3 \%(349 / 3,389)$ associated with crush syndrome, other injuries, and illness, respectively. The overall mortality rate was $8.6 \%(527 / 6,107$ patients). Morbidity as well as mortality rates increased with age of the patients with both injuries and illnesses. Of the total of 2,718 trauma patients, intensive care was required for 262 (9.6\%) patients with crush syndrome and 301 (11.1\%) patients with other types of injuries. Two-hundred-two patients (77.1\%) with crush syndrome developed acute renal failure, $60.9 \%$ of whom required hemodialysis. All cases of crush syndrome were caused by collapsing houses. Conclusions: During the initial 15-day period, there were an unprecedented number of patients suffering from trau$\mathrm{ma}$, and they converged upon the affected hospitals. Subsequently, an increased incidence of illness was observed. This survey underscores the need for adequate disaster response in such an urban situation.

Keywords: census; collapsed building; crush syndrome; data; diagnosis; earthquake; Hanshin-Awaji; injuries; mortality; prognosis; records Prehosp Disast Med 2002;17:s18.

\section{Chartered Helicopters in Readiness for Catastrophe} Masabiro Takiguchi, $M D$

Department of Emergency and Critical Care Medicine, Hirosaki University Hospital, Japan

One of the serious problems for the disaster relief mission when the Great Hanshin-Awaji Earthquake occurred on 17 January 1995 in the Hanshin area of Japan, was that although many helicopters were available, no helicopters were used to provide effective medical evacuation and transportation. The major cause was that since medical doctors previously had not used helicopter for patient transports, no operational anti-disaster helicopter system to transport severely injured patients from the disaster sites in Kobe to undamaged places, had been established,.

After the Great Hanshin-Awaji Earthquake, the Fire and Disaster Management Agency, a department of the Government, intended to use helicopters for the rescue and transportation of emergency patients. However, it had not been practiced. Therefore, the Ministry of Health, Labour, and Welfare of the Government has established an organization that involves a system to immediately hire and use chartered helicopters from commercial helicopter operators if it becomes necessary in case of a catastrophe. This system now is under the preparation and soon will be introduced in the form of a contract with the Tokyo Metropolitan Government, as one element of preparation for a massive earthquake that likely will happen in the near future in south Kantoh areas.

Keywords: catastrophe; chartered commercial helicopter; earthquake; system; Tokyo Metropolitan Government

Prehosp Disast Med 2002;17:s18. 